\title{
KARAKTERISASI SENYAWA BIOAKTIF ANTIMIKROBA EKSTRAK UMBI BAWANG TIWAI (Eleutherine bulbosa (MILL.) URB.)
}

\author{
Mahfuzun Bone $^{1 *}$, Yusnita Rifai ${ }^{2}$, Gemini Alam $^{3}$ \\ ${ }^{1}$ Fakultas Farmasi Universitas Mulawarman, Samarinda, Indonesia \\ ${ }^{2}$ Fakultas Farmasi Universitas Hasanuddin \\ *Email korespondensi: fuzunpharm31@gmail.com
}

\begin{abstract}
E. bulbosa is a typical plant in Kalimantan, this plant has been used for generations by Dayak community as an antibacterial. This study aimed to determine the characterization of E. bulbosa active antimicrobial compound. The first stage of this research is extraction E. bulbosa using methanol and liquid partition using n-hexane, ethyl acetate, n-butanol. Antimicrobial screening test extracts of methanol, n-hexane, ethyl acetate, n-butanol concentrations $1 \mathrm{mg} / \mathrm{mL}$. Extraction of $n$-hexane fractionation by vacuum liquid chromatography and then refractionation by using sepacore. The active fraction isolation by using thin layer chromatography preparative, obtained E. bulbosa active isolates. Characterization active isolates E. bulbosa by Identification based on chromatogram showed E. bulbosa active isolates is class of naphthalene. The interpretation FTIR spectroscopy of E. bulbosa active isolates indicates the group-OH, $\mathrm{CH}$ alifatis, and $\mathrm{C}=\mathrm{O}$. The ${ }^{1} H$ NMR spectrum of E. bulbosa active isolates indicates spectrum of $H-6$ at $\delta$ 6,92 ppm Mult. doblets and $\mathrm{J} 10,5 \mathrm{~Hz}$, spectrum of $\mathrm{H}-8$ at $\delta$ 7,75 ppm, Mult. doblets and $\mathrm{J} 10,5 \mathrm{~Hz}$, spectrum of $H-9$ at $\delta$ 6,29 ppm, and spectrum $H-11$ at $\delta 3,21$ ppm. Minimum inhibitory concentration of E. bulbosa active isolates for $V$. cholera, B. subtilis, S. mutans, S. aureus 125 ppm and E. coli 250 ppm. Concluded the E. bulbosa active isolates show compound class of naftalen and has antimicrobial activity.
\end{abstract}

Key words: E. bulbosa, Characterization, Antimicrobial Potential

\begin{abstract}
ABSTRAK
Eleutherine bulbosa adalah tanaman khas suku Kalimantan yang telah digunakan secara turun-temurun sebagai antibakteri. Penelitian ini bertujuan untuk menentukan karakterisasi senyawa aktif antimikroba E. bulbosa. Tahapan penelitian diawali dengan ekstraksi E.bulbosa dengan pelarut metanol dan partisi cair-cair menggunakan pelarut n-heksan, etil asetat, n-butanol. Uji Skrining antimikroba ekstrak methanol, n-heksana, etil asetat, dan nbutanol dengan konsentrasi $1 \mathrm{mg} / \mathrm{mL}$. Ekstrak n-heksana difraksinasi dengan kromatografi cair vakum dan direfraksinasi kembali menggunakan sepacore. Fraksi aktif diisolasi dengan kromatografi lapis tipis preparatif dan diperoleh isolat aktif E. bulbosa. Hasil Identifikasi berdasarkan kromatogram menunjukkan isolat aktif E.bulbosa adalah golongan naphthalene. interpretasi data spektroskopi FTIR isolat aktif E.bulbosa menunjukkan adanya gugus $\mathrm{OH}$ hidroksil, $\mathrm{CH}$ alifatik, dan $\mathrm{C}=\mathrm{O}$. Hasil Interpretasi data ${ }^{1} \mathrm{H}$ NMR isolat aktif E. bulbosa menunjukkan Data ${ }^{1} \mathrm{H}$ NMR memperlihatkan adanya spektrum dari atom $\mathrm{H}-6$ dengan nilai $\delta 6,92 \mathrm{ppm}$ Mult. doblet dan J 10,5 Hz, spektrum dari atom $\mathrm{H}-8$ dengan nilai $\delta$ 7,75 ppm, Mult. doblet dan $\mathrm{J} 10,5 \mathrm{~Hz}$, spektrum dari atom H-9 dengan nilai $\delta 6,29 \mathrm{ppm}$, dan spektrum H-11 dengan nilai $\delta 3,21 \mathrm{ppm}$. Nilai Konsentrasi Hambat Minimum (KHM) isolat aktif E.bulbosa terhadap bakteri uji V. cholera, B. subtilis, S. mutans, S. aureus $0,0125 \%$ dan
\end{abstract}


bakteri $E$. coli $0,025 \%$. Disimpulkan bahwa isolat aktif E. bulbsoa adalah golongan senyawa naftalen dan memiliki aktivitas antimikroba.

Kata Kunci: E. bulbosa, Karakterisasi, Potensi antimikroba

DOI: https://doi.org/10.25026/jsk.v2i1.119

\section{PENDAHULUAN}

Masyarakat Indonesia sejak dahulu telah mengenal dan memanfaatkan tumbuhan berkhasiat obat dalam penanggulangan masalah kesehatan baik berupa pencegahan maupun pengobatan. Pemanfaatan tumbuhan obat tersebut merupakan pengetahuan dan pengalaman yang diwariskan secara turun-temurun oleh nenek moyang mereka, sehingga dihasilkan berbagai ramuan herbal yang merupakan ciri khas penggunaan obat tradisional Indonesia [1].

E. palmifolia dari famili iridaceae merupakan satu dari sekian banyak tumbuhan obat yang telah digunakan secara luas sebagai obat tradisional. Bagian umbi dari tumbuhan ini telah digunakan pada resiko kanker otak oleh masyarakat lokal di Kalimantan, juga pada resiko kerusakan hati, sebagai imunostimulan, anti-inflamasi, dan antitumor [2],[3]. Pada penelitian sebelumnya menunjukan $E$. bulbosa mengandung beberapa senyawa aromatik dan senyawa glikosida seperti eleuterinon, eleuterin, isoeleuterin, eleuterol [4].

Le dkk (2012), selama skirining tanaman obat untuk aktivitas antiinflamasi, menemukan bahwa ekstrak metanol dari E. bulbosa berpotensi menghambat lipopolisakarida untuk merangsang produksi IL-12 p40 dan IL-16 sitokin di sumsum tulang yang berada di sel dendritik dengan dinilai IC $_{50}$ masingmasing $0,1 \pm 0,05$ dan 16,2 $\pm 0,3 \mu \mathrm{g} / \mathrm{Ml}$ [5]. Lebih lanjut Budityastomo (2010), menjelaskan dalam menghambat ekspresi Cyclin-E pada fraksi etanol E. palmifolia menunjukkan pada konsentrasi 18,75 $\mu \mathrm{g} / \mathrm{mL}, \quad 37,5 \mu \mathrm{g} / \mathrm{mL}$, dan $75 \mu \mathrm{g} / \mathrm{mL}$ menyebabkan penurunan ekspresi cyclinE masing-masing $65 \%, 38,7 \%$, dan $4 \%$ [6].

Ifesan dkk (2010), menguji aktivitas antimikroba ekstrak etanol E. americana pada beberapa mikroba. Hasilnya menunjukkan nilai konsentrasi minimum yang dapat menghambat pertumbuhan mikroba (MIC) terhadap bakteri bacillus subtilis $0,125 \mathrm{mg} / \mathrm{mL}$., Staphylococcus aureus $0,25 \mathrm{mg} / \mathrm{mL}$, Streptococcus spp. $0,25 \mathrm{mg} / \mathrm{Ml}$ [7]. Lebih lanjut Kalidass dkk (2012), menguji aktivitas antibakteri ekstrak kasar E. americana terhadap bakteri Streptococcus sp. Ekstrak menunjukkan pada konsentrasi 0,1 $\mathrm{mg} / \mathrm{mL}$ dapat menghambat bakteri Streptococcus sp [8].

Tujuan penelitian ini untuk menentukan karakterisasi senyawa aktif ekstrak E. bulbosa dan mengetahui potensi antimikroba dari ekstrak tersebut.

\section{METODE}

\section{Lokasi dan Rancangan Penelitian}

Penelitian ini adalah penelitian eksperimental. Penelitian ini dilakukan di Laboratorium Mikrobiologi dan Bioteknologi Fakultas Farmasi Universitas Hasanuddin, Laboratorium Biofarmaka Pusat Kegiatan Penelitian Universitas Hasanuddin, dan Laboratorium Dendrologi Fakultas Kehutanan Universitas Mulawarman. Jenis penelitian adalah experimental laboratories.

\section{Metodologi Penelitian}

Sampel E.bulbosa diperoleh dari kota samarinda Kalimantan Timur. Ekstrak E.bulbosa diperoleh dengan mengekstraksi E. bulbosa menggunakan 
pelarut metanol dan dipartisi cair-cair menggunakan pelarut n-heksan, etil asetat, dan n-butanol. Ekstrak yang diperoleh diuji skrining antimikroba terhadap bakteri E. coli, $S$. aureus, S. mutans, B. subtilis, $S$. disentri, $V$. cholera, $P$. aureginosa, $C$. albicans pada medium Glukosa Nutrien Agar (GNA) menggunakan metode difusi padat dengan konsentrasi $0,1 \%$. Suspensi bakteri dibuat berdasarkan kekeruhan dari larutan 0,5 Mc Farland sebagai standar. Ekstrak n-heksan yang memiliki aktivitas antimikroba paling baik difraksinasi dengan Kromatografi Cair Vakum (KCV) dan refraksinasi dengan Sepacore menggunakan eluen n-heksan - etil asetat. Subfraksi E.bulbosa diisolasi dengan Kromatografi Lapis Tipis Preparatif (KLTP) menggunakan eluen n-heksan etil asetat (7:3).

Isolat E. bulbosa yang diperoleh selanjutnya dikarakterisasi menggunakan pereaksi semprot $\mathrm{KOH}$ etanolik $10 \%$ I $\mathbf{T}$. Vis, FTIR, ${ }^{1} \mathrm{H}$ NMR. Pengujian $\mathrm{pr}{ }^{7}$ i antimikroba isolat aktif E. bulbosa menggunakan metode dilusi cair terhadap bakteri E.coli, V. cholera, B. subtilis, S.aureus, dan $S$. mutans untuk menentukan Kadar Hambat Minimum (KHM), dimana konsentrasi yang digunakan $0,1 \%, \quad 0,05 \%, \quad 0,025 \%$, $0,0125 \%$, dalam medium Glukosa Nutrien Broth (GNB). Uji lanjutan potensi antimikroba dengan metode difusi agar menggunakan paper disc, dimana konsentrasi yang digunakan $0,1 \%, 0,05$, $0,025 \%, \quad 0,0125 \% \quad$ (konsentrasi berdasarkan uji KHM) pada medium GNA. Pelarut DMSO sebagai Kontrol negatif dan antibiotik kloramfenikol $0,0125 \%$ sebagai kontrol positif.

\section{HASIL DAN PEMBAHASAN}

Hasil dari ekstraksi dan partisi cair-cair umbi $E$. bulbosa diperoleh ekstrak metanol sebanyak $101,58 \mathrm{~g}$, ekstrak n-heksan 24,59 g, ekstrak etil asetat 13,79 g, dan ekstrak n-butanol 9,86. Hasil identifikasi isolat aktif E. bulbosa menggunakan pereaksi semprot $\mathrm{KOH}$ etanolik $10 \%$ menghasilkan warna merah pada UV $366 \mathrm{~nm}$. Hasil Karakterisasi isolat aktif E. bulbosa dengan FTIR diperoleh puncak serapan $3439 \mathrm{~cm}^{-1}$ menunjukkan gugus $(\mathrm{OH})$, puncak serapan 2926 dan $2856 \mathrm{~cm}^{-1}$ menunjukkan gugus $\mathrm{CH}$ alifatik, puncak serapan 1564 dan $1460 \mathrm{~cm}^{-1}$ menunjukkan cincin aromatik, puncak serapan $1732 \mathrm{~cm}^{-1}$ menunjukkan gugus $\mathrm{C}=\mathrm{O}$, puncak serapan $1651 \mathrm{~cm}^{-1}$ menunjukkan Gugus $\mathrm{C}=\mathrm{C}$ (Gambar 1). Karakterisasi dengan ${ }^{1} \mathrm{H}$ NMR $\left(\mathrm{CD}_{3} \mathrm{OD}, 500 \mathrm{MHz}\right)$ menunjukkan adanya spektrum pada $\delta 6,92 \mathrm{ppm}(1 \mathrm{H}, \mathrm{d}$, $\mathrm{J}=10,5 \mathrm{~Hz}, \mathrm{H}-6), \delta 7,75 \mathrm{ppm}(1 \mathrm{H}, \mathrm{d}, \mathrm{J}=$ $10,5 \mathrm{~Hz}, \mathrm{H}-8), \delta 6,29 \mathrm{ppm}(1 \mathrm{H}, \mathrm{s}, \mathrm{H}-9), \delta$ 3,01 ppm (3H, s, $\left.\mathrm{OCH}_{3}-11\right)$ (Gambar 2). Data identifikasi isolat aktif E. bulbosa identik dengan truktur eleutherol (Gambar 3). Uji potensi antimikroba isolat aktif $E$. bulbosa diperoleh nilai MIC untuk bakteri $V$. cholera, B. subtilis, S. aureus, $S$. mutans adalah $0,0125 \%$ dan untuk bakteri E.coli adalah $0,025 \%$ (Tabel 1), sedangkan uji lanjutan potensi antimikroba diperoleh diameter daya hambat pada konsentrasi $0,1 \%$; $0,05 \%$; $0,025 \% ; 0,0125 \%$ untuk semua bakteri kecuali E. coli pada konsentrasi $0,1 \%$; $0,05 \% ; 0,025 \%$ (Tabel 2).

Penelitian ini menunjukkan bahwa isolat aktif $E$. bulbosa termasuk golongan senyawa naftalen dan memiliki potensi antimikroba terhadap bakteri gram positif dan negatif. Hal ini disebabkan adanya kandungan senyawa naftalen pada isolat aktif E. bulbosa.

Dalam penelitian ini zat aktif yang terkandung dalam E. bulbosa diekstraksi menggunakan metode maserasi untuk menarik senyawa polar dan nonpolar. Kemudian dipartisi cair-cair menggunakan n-heksan, etil asetat, dan nbutanol untuk memisahkan senyawa dari ekstrak metanol berdasarkan tingkat kepolaran. Ekstrak n-heksan yang memiliki aktivitas antimikroba paling difraksinasi untuk memperoleh isolat aktif. 
Isolat aktif E. bulbosa yang diperoleh dikarakterisasi dengan uji kromatogram pereaksi semprot menggunakan pereaksi $\mathrm{KOH}$ etanolik. Hasil karakterisasi pereaksi semprot $\mathrm{KOH}$ etanolik menunjukkan warna merah setelah pemanasan dengan $110^{\circ} \mathrm{C}$ selama 15 menit. Hal ini menunjukkan isolat aktif diduga termasuk ke dalam golongan senyawa naphtalene.

Hasil identifikasi spektroskopi FTIR menunjukkan puncak serapan pada panjang gelombang $3439 \mathrm{~cm}^{-1}$ merupakan gugus hidroksil $(\mathrm{OH})$. Pita serapan 2926 dan $2856 \mathrm{~cm}^{-1}$ menunjukkan gugus $\mathrm{CH}$ alifatik yang diperkuat dengan puncak serapan 1564 dan $1460 \mathrm{~cm}^{-1}$ yang menunjukkan cincin aromatik. Puncak serapan $1732 \mathrm{~cm}^{-1}$ menunjukkan adanya gugus $\mathrm{C}=\mathrm{O}$. Gugus $\mathrm{C}=\mathrm{C}$ menunjukkan puncak serapan didaerah $1651 \mathrm{~cm}^{-1}$. Berdasarkan interpretasi data IR menunjukkan isolat $\mathrm{C} 4 \mathrm{~d}$ mengandung gugus $\mathrm{OH}, \mathrm{CH}$ alifatik, $\mathrm{C}=\mathrm{O}$, dan $\mathrm{C}=\mathrm{C}$ [9].

Hasil Interpretasi data ${ }^{1} \mathrm{H}$ NMR isolat aktif ditelusuri dengan membandingkan spektra ${ }^{1} \mathrm{H}$ NMR yang dilaporkan oleh Leyama dkk (2011). Karakteristik spektra ${ }^{1} \mathrm{H}$ NMR isolat aktif terutama berasal dari proton yang terletak pada cincin aromatik di area $\delta$ (chemical shift) $6,00-7,00$ ppm. Data ${ }^{1} \mathrm{H}$ NMR isolat aktif memperlihatkan adanya spektrum dari atom H-6 yang memiliki 2 proton $\mathrm{H}$ tetangga (doblet) terhadap atom $\mathrm{H}-7$ dengan nilai $\delta 6,92 \mathrm{ppm}$ dan nilai kopling konstan $10,5 \mathrm{~Hz}$, spektrum dari atom $\mathrm{H}-8$ yang memiliki 2 proton $\mathrm{H}$ tetangga (doblet) terhadap atom $\mathrm{H}-7$ dengan nilai $\delta$ 7,75 ppm dan nilai kopling konstan 10,5 Hz, Spektrum dari atom H-9 singlet dengan nilai $\delta \quad 6,29 \mathrm{ppm}$, dan spektrum $\mathrm{H}-11$ singlet dengan nilai $\delta 3,21$ ppm.

Tabel 1. Hasil pengujian Kadar Hambat Minimum (KHM) isolat aktif (C4d) E. Bulbosa

\begin{tabular}{lccccc}
\hline \multirow{2}{*}{ Konsentrasi Uji } & \multicolumn{5}{c}{ Bakteri Uji } \\
\cline { 2 - 6 } \multicolumn{1}{c}{} & Bs & Vc & Ec & Sm & Sa \\
\hline $1000 \mathrm{ppm}$ & + & + & + & + & + \\
$500 \mathrm{ppm}$ & + & + & + & + & + \\
$250 \mathrm{ppm}$ & + & + & + & + & + \\
$125 \mathrm{ppm}$ & + & + & - & + & + \\
$62,5 \mathrm{ppm}$ & - & - & - & - & - \\
$31,25 \mathrm{ppm}$ & - & - & - & - & - \\
Kontrol (+) & - & - & - & - & - \\
Kontrol (-) & + & + & + & + & + \\
\hline
\end{tabular}

Tabel 2. Hasil uji lanjutan potensi antimikroba isolat aktif C4d E. bulbosa

\begin{tabular}{lccccc}
\hline \multirow{2}{*}{ Konsentrasi Uji } & \multicolumn{5}{c}{ Diameter Zona Hambat $(\mathrm{mm})$ terhadap Bakteri Uji } \\
\cline { 2 - 6 } & Bs & Vc & Ec & Sm & Sa \\
\hline $1000 \mathrm{ppm}$ & 14,16 & 13,28 & 13,35 & 20,33 & 27,23 \\
$500 \mathrm{ppm}$ & 12,75 & 12,75 & 11,25 & 18,15 & 25,73 \\
$250 \mathrm{ppm}$ & 11,30 & 10,28 & 9,75 & 15,73 & 19,60 \\
$125 \mathrm{ppm}$ & 9,28 & 8,27 & - & 13,20 & 16,93 \\
Kontrol (+) & 17,75 & 15,88 & 16,33 & 22,42 & 28,83 \\
Kontrol (-) & - & - & - & - & - \\
\hline
\end{tabular}




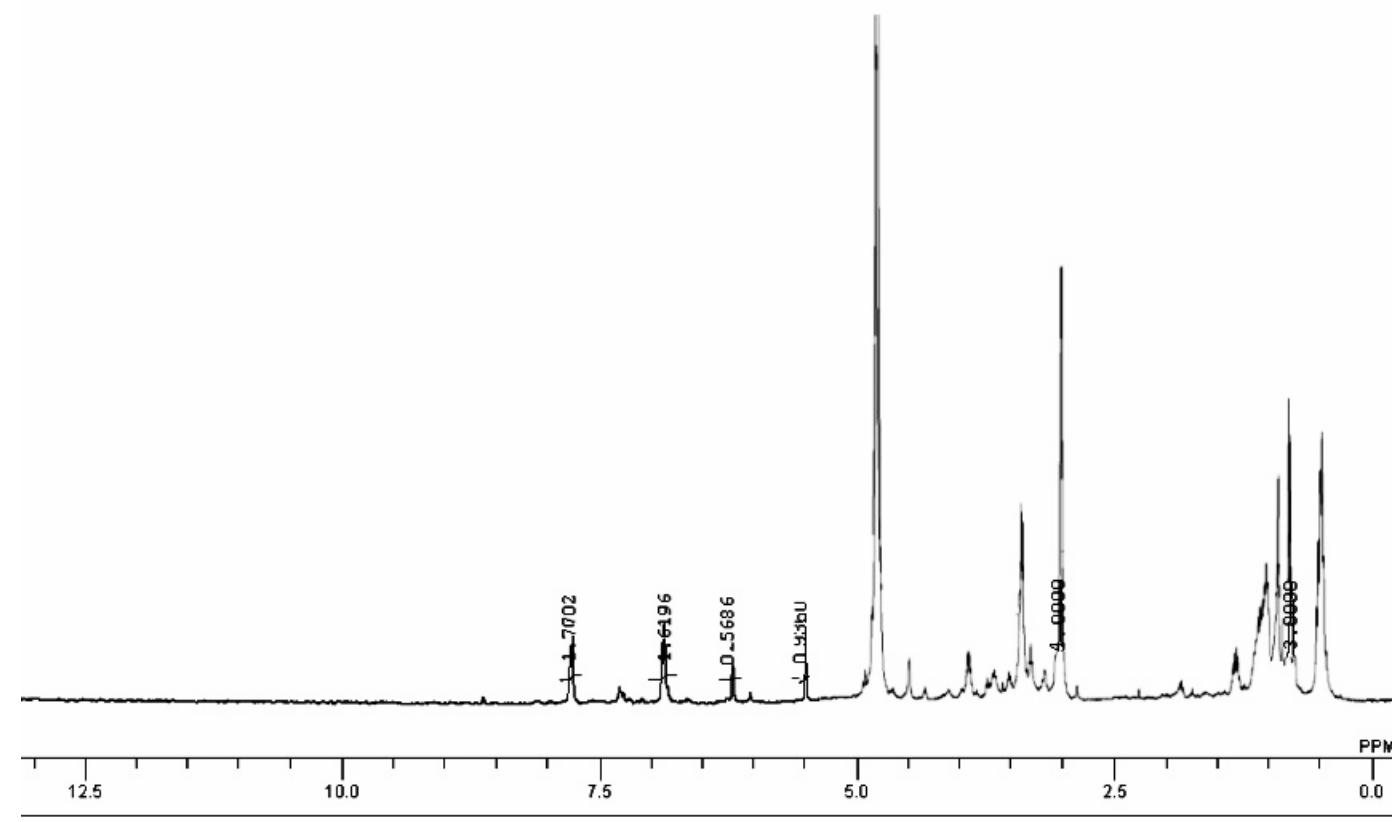

Gambar 1. Data spektra 1H NMR (500 MHz) isolat aktif E. bulbosa

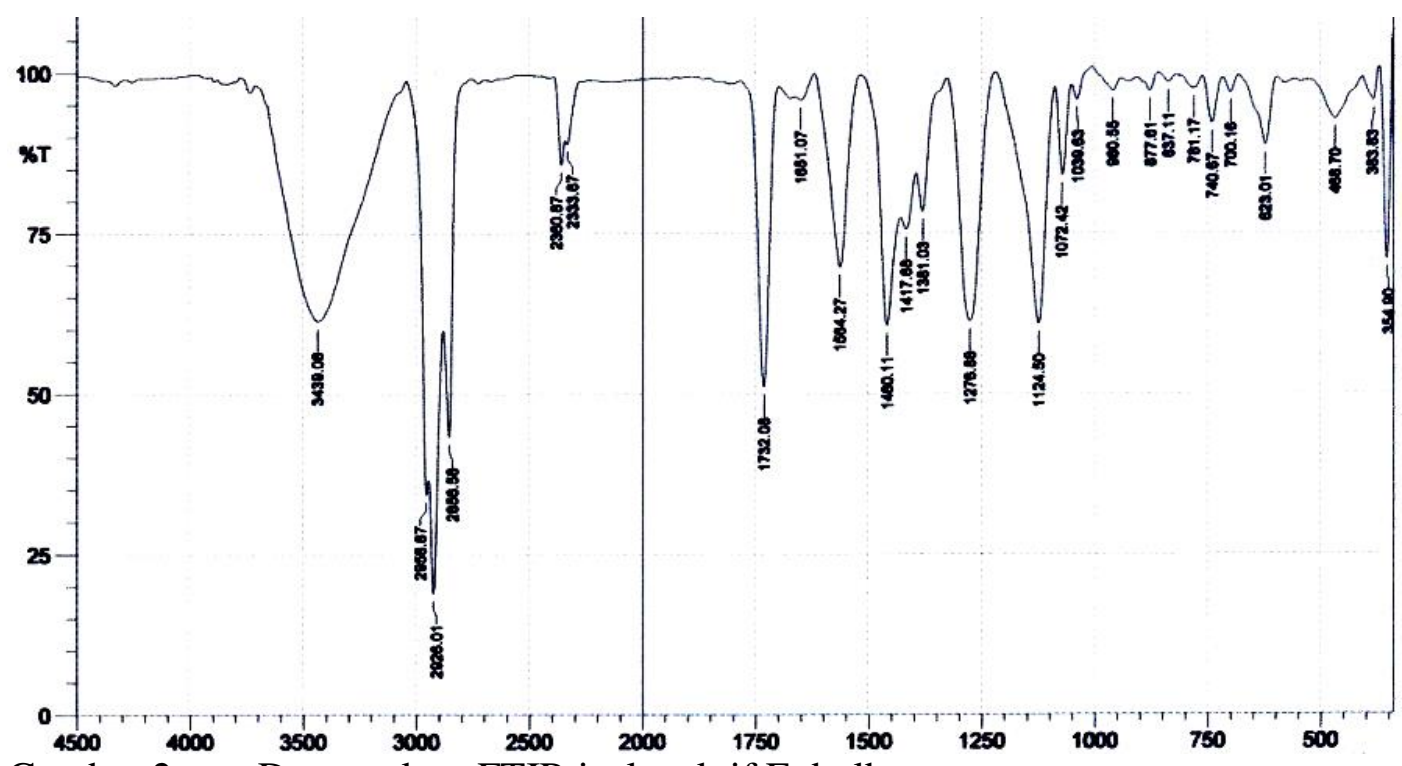

Gambar 2. Data spektra FTIR isolat aktif E. bulbosa

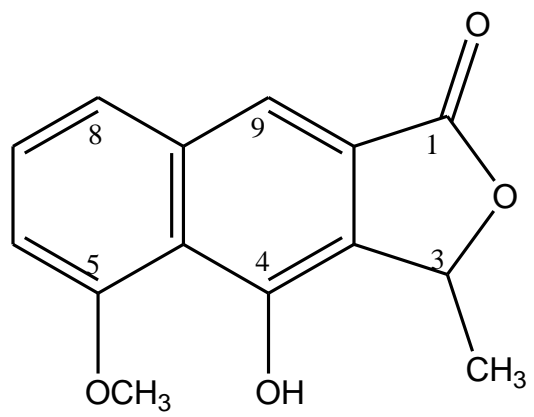

Gambar 3. Struktur senyawa eleutherol 
Jika melihat hasil interpretasi ${ }^{1} \mathrm{H}$ NMR isolat aktif terdapat beberapa kesamaan dari spektra ${ }^{1} \mathrm{H}$ NMR yang dilaporkan oleh Leyama dkk (2011), adanya spektrum yang muncul pada $\delta$ 6-7 ppm yang menandakan cincin aromatik, $\delta$ 3-5 ppm dengan integral 3H menandakan gugus metoksi $\left(\mathrm{OCH}_{3}\right)$. Akan tetapi ada beberapa spektrum multiplet yang muncul pada isolat aktif pada $\delta 0,91 \mathrm{ppm}$ dan 5,06 ppm. Hasil ini membedakan dengan spektra yang dilaporkan oleh Leyama dkk (2011), ini terjadi kemungkinan disebabkan oleh tingkat kemurnian isolat aktif hanya sekitar $75 \%$ sehingga menyebabkan ketidakstabilan peak yang muncul pada saat pengukuran ${ }^{1} \mathrm{H}$ NMR [10].

Berdasarkan data ${ }^{1} \mathrm{H}$ NMR isolat aktif dan dibandingkan dengan hasil penelitian yang dilaporkan oleh Leyama dkk (2011), maka kemungkinan rumus struktur isolat aktif E. bulbosa adalah eleutherol $\left(\mathrm{C}_{14} \mathrm{H}_{14} \mathrm{O}_{4}\right)$ [10].

Isolat aktif $E$. bulbosa selanjutnya dilakukan pengujian potensi antimikroba dengan metode dilusi cair pada konsentrasi $\quad 0,1 \% ; \quad 0,05 \% ; \quad 0,025 \%$; $0,0125 \%$ untuk mengetahui kadar hambat minimum (KHM). Metode dilusi cair biasa digunakan dalam pengujian aktivitas antmikroba yang didasarkan pada prinsip pengenceran. Prinsip dari metode ini adalah pengenceran larutan uji sampai diperoleh seri konsentrasi pada masingmasing larutan uji ditambah suspensi bakteri [11]. Hal ini yang akan menyebabkan terjadinya interaksi yang homogen antara larutan uji dengan suspensi bakteri sehingga penghambatan bakteri lebih sensitif. Selain itu, pada metode ini penggunaan media dan bahan uji lebih hemat dan tidak dipengaruhi oleh tebal tipisnya media dan faktor difusibilitas bakteri uji. Hasil pengujian KHM isolat aktif terhadap bakteri $E$. coli terlihat pada konsentrasi $0,025 \%$ dan bakteri B. subtilis, $V$. cholera, S. mutans, $S$. aureus terlihat pada konsentrasi $0,0125 \%$. Hasil pengujian KHM ini menjadi acuan untuk uji potensi antimikroba selanjutnya.

Uji lanjutan potensi antimikroba isolat aktif $E$. bulbosa menggunakan metode difusi agar padat pada beberapa variasi konsentrasi. Metode ini digunakan karena cukup sederhana dan efektif untuk mengetahui aktivitas antibakteri suatu sampel [11]. Hasil uji lanjutan potensi antimikroba isolat aktif menunjukkan penghambatan hingga konsentrasi 0,0125\% untuk bakteri Bacillus subtilis, Vibrio cholera, Streptococcus mutans, Staphylococcus aureus. dan untuk bakteri Escherichia coli menunjukkan penghambatan hingga konsentrasi $0,025 \%$.

Berdasarkan hasil pengamatan zona hambat isolat aktif E. bulbosa, menunjukkan potensi antimikroba tersebut efektif terhadap bakteri gram negatif dan gram positif, sehingga dapat dikatakan isolat aktif sebagai senyawa aktif berspektrum luas. Kontrol positif yang digunakan adalah kloramfenikol dengan konsentrasi $0,0125 \%$ menunjukkan potensi lebih besar pada seluruh bakteri uji. Ibtissam dkk (2009), menjelaskan parameter kekuatan daya antibakteri, daerah hambatan $20 \mathrm{~mm}$ atau lebih termasuk aktivitas sangat tinggi, 16$19 \mathrm{~mm}$ termasuk aktivitas tinggi, 10-15 $\mathrm{mm}$ termasuk kategori sedang, dan daerah kurang dari $10 \mathrm{~mm}$ termasuk kategori rendah. Berdasarkan teori tersebut, isolat aktif $E$. bulbosa memiliki aktivitas sedang untuk bakteri gram positif dan aktivitas rendah untuk bakteri gram negative [12].

\section{KESIMPULAN DAN SARAN}

Isolat aktif E. bulbosa adalah golongan naphthalene dan memiliki aktivitas sebagai antimikroba. Melihat potensi tersebut, maka diharapkan ke depannya Perlu didukung data MS, ${ }^{13} \mathrm{C}$ NMR, dan NMR dua dimensi sehingga struktur senyawa aktif yang diperoleh dapat diketahui dengan pasti dan dilakukan pengembangan lebih lanjut 
kearah formulasi sediaan farmasi khususnya sediaan obat antibiotik.

\section{DAFTAR PUSTAKA}

[1]. Litbang Depkes. (2011). Tanaman Obat Asli Milik Masyarakat Bangsa dan Negara RI. http://www.bmf.litbang.depkes.go. id.

[2]. Sa'roni P, Nurendah, Adjirni. (1987). Penelitian efek anti inflamasi beberapa Tanaman obat pada tikus putih. Konggres Biologi Nasional VIII. Purwokerto. 8-10 Oktober.

[3]. Saptowalyono C.A. (2007). Bawang dayak, tanaman obat kanker yang belum tergarap. www.kompas.com.

[4]. Alves T.M.A., Helmut K, Carlos L.Z. (2003). Eleutherinone a novel fungitoxic naphtoquinone from Eleutherine bulbosa (Iridaceae). Mem Inst Oswaldo Cruz, Rio de Janeiro, Vol. 98(5): 709-712.

[5]. Le Min Ha, P.V. Kiem, C.V. Minh. (2012). Chemical Constituents of the Rhizome of Eleutherine Bulbosa and Their Inhibitory Effect on the Pro-Inflamatory Cytokines Production in LipopolysaccharideStimulated Bone Marrow-Derived Dendritic Cells. Bull. Korean Chem. Soc. Vol. 34, No. 2. 633.

[6]. Budiyastomo H. (2010). Tesis: Pengaruh Pemberian Fraksi Etanolik Ekstrak Bawang Dayak terhadap Tingkat Ekspresi Cyclin E Galur Sel Kanker Serviks Uteri Hela (Human Papiloma Virus High
Risk Type). Fakultas Kedokteran Universitas Sebelas Maret.

[7]. Ifesan B.O., Ibrahim D., and S.P. Voravuthikunchai. (2010). Antimicrobial Activity of Crude Ethanolic Extract from Eleutherine Americana. Thailand. Journal of Food. agriculture \& environment Vol. 8 (3 \& 4) 1233-1236.

[8]. Kalidass S., Sembian S., Femina W., Febina B.S., Gilbert R.R. (2012). Antagonistic Activity of Eleutherine Palmifolia Linn. Karunya Institute of Technology and Sciences. India. Asian Pacific Journal of Tropical Disease S491S493.

[9]. Silverstein R.M., Webster F.X., Kiemle D.J. (2005). Spectrofotometric Identification of Organik Compounds. Seventh Edition. State University of New York. Hal. 83 - 87.

[10]. Leyama T., Maria D.P.T., Jun K. (2011). a Glucosidase Inhibitors From the Bulb Of Eleutherine Americana. Japan. Journal of Food Chemistry 128 (2011) 308 - 311.

[11]. Jawertz M. \& Aldelberg's A. (2001). Mikrobiologi Kedokteran. Universitas Airlangga. Salemba Medika. Jakarta.

[12]. Ibtissam C., Hassane R., Jose M.L., Fransisco D.S.J., Antonio G.V.J., Hassan B., dkk. (2009). Screening of Antibacterial Activity in Marine Green and Brown Macroalgae from the Coast of Marocco. African Journal of Biotechnology. Vol. 8 (7): $1258-1262$. 